\title{
O USO DO IVDN NO ESTUDO DA DEGRADAÇÃO AMBIENTAL DA BACIA HIDROGRÁFICA DO RIO GRAMAME, PARAÍBA
}

\author{
THE NVDI USE IN THE ENVIRONMENTAL DEGRADATION STUDY OF THE GRAMAME \\ RIVER BASIN, PARAÍBA STATE
} \author{
Universidade Federal da Paraíba - UFPB. Centro de Tecnologia. Departamento de Engenharia Civil e Ambiental. João Pessoa - \\ Paraíba. Emails: alysson-lucena@hotmail.com; deco86@gmail.com; hfilgueira@gmail.com.

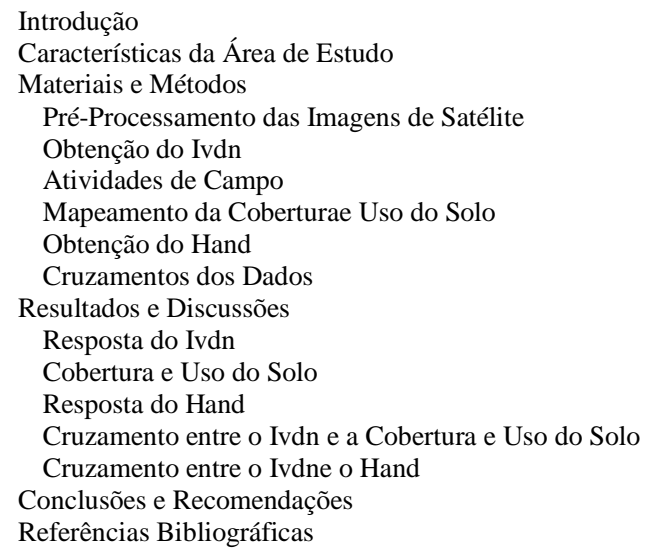

Alysson Pereira de LUCENA; André Lucena PIRES; Hamilcar José Almeida FILGUEIRA

RESUMO - Este trabalho teve como objetivo a aplicação do Índice de Vegetação por Diferença Normalizada (IVDN) no estudo da degradação ambiental da bacia hidrográfica do rio Gramame, Paraíba, a partir da utilização de imagens do satélite TM/Landsat-5, dos anos de 1989, 2001 e 2006. Foram feitas correções atmosférica e radiométricas para confeccionar os mapas temáticos do IVDN e de cobertura e uso do solo, realizadas visitas in loco e confeccionados os mapas da descrição do terreno em relação à rede de drenagem, utilizando o algoritmo Height Above the Neareast Drainage (HAND). A partir do cruzamento do IVDN com o HAND foi verificada a presença de vegetação com maior biomassa nas regiões com menores cotas altimétricas da bacia hidrográfica. O cruzamento dos mapas de cobertura e uso do solo e do IVDN mostrou que grande parte das áreas com solos expostos apresentou valores de IVDN próximos de zero. Quanto à degradação da vegetação na bacia hidrográfica, houve uma diminuição dos valores de IVDN de 1989 para 2001 e uma regeneração de 2001 para 2006.

Palavras-chave: Uso do solo; cobertura vegetal; geotecnologias.

\begin{abstract}
The objective of this study was to apply the Normalized Difference Vegetation Index (NDVI) in the assessment of the environmental degradation of the Gramame river basin, Paraíba State, using TM/Landsat-5 satellite images from 1989, 2001 and 2006. Atmospheric and radiometric corrections were made in order to create thematic maps of the NDVI and the land cover and land use. On-site visits were made and the land description maps were drawn up in relation to the drainage network system using the Height Above the Nearest Drainage (HAND) algorithm. From the cross-sectional analysis of the NDVI and HAND, the presence of vegetation with greater biomass was observed in lower altitude regions of the hydrographic basin. Furthermore, the cross-sectional analysis of the land cover and land use maps with the NDVI showed that most of the bare soil areas presented NDVI values close to zero. With regard to the vegetation degradation of the river basin, the NDVI values decreased from 1989 to 2001, but then improved from 2001 to 2006.
\end{abstract}

Keywords: Land use; vegetation cover; geotechnology.

\section{INTRODUÇÃO}

As transformações realizadas pelo homem, geralmente ocorrem sem considerar as características do meio ambiente e são influenciadas por fatores espaciais e temporais que interagem com os recursos das bacias hidrográficas. Segundo Timothy \& Olga (2011), analisar essas mudanças torna-se fundamental para avaliar os padrões de cobertura e uso do solo e seus impactos.

As degradações dos recursos naturais vêm causando, além de impactos ambientais, negativas consequências socioeconômicas, como a falta de oportunidades que leva a população a migrar para as cidades, tendendo a agravar os problemas de infraestrutura, pobreza, injustiça social, desemprego e violência (Mello \& Lima, 2011).

Para Schimdt \& Morrison (2012) as degradações provocam consequências socioambientais, que devem ser estudadas de forma holística, considerando as relações entre a bacia hidrográfica, seu ecossistema e a sociedade. De acordo com Ferreira et al. (2011), estudos ambientais em bacias hidrográficas são fundamentais para o entendimento do uso dos recursos naturais e, 
dos problemas relacionados à ocupação do espaço, visando dar suporte às ações de recuperação ambiental, considerando as formas de cobertura e uso do solo e as necessidades das comunidades.

Para o uso sustentável dos recursos naturais é essencial um monitoramento e planejamento adequado. Informações oportunas e precisas sobre o uso do solo, a cobertura vegetal, sua distribuição espacial e as alterações ao longo do tempo são necessárias para a identificação das áreas ecologicamente importantes e sua orientação para o crescimento futuro (Deb \& Talukdar, 2011).

Nesse contexto, estudos apoiados em geotecnologias podem integrar informações que geram respostas com alto grau de confiabilidade e possibilitam avanços, em ações de planejamento e em processos de gestão e manejo do espaço geográfico (Fitz, 2008). Essa integração de informações possibilita a manipulação e interpretação de grandes conjuntos de dados, gerando índices de razão de bandas espectrais e algoritmos, como por exemplo o Indice de Vegetação por Diferença Normalizada (IVDN) e o Height Above the Neareast Drainage (HAND), respectivamente.

O IVDN, proposto por Rouse Júnior et al. (1973), resulta da relação normalizada entre os níveis de reflectância, nas bandas do vermelho e do infravermelho próximo. Essas bandas estão diretamente relacionadas com os parâmetros biofísicos da vegetação.

A consistência espaço-temporal do IVDN, como representante da dinâmica da vegetação, pode fornecer vantagens, em relação à aplicação da metodologia de refletância de multiresolução, pois a partir do IVDN é possível verificar a densidade e o vigor da vegetação, bem como, se há alterações ambientais, naturais ou antrópicas em uma determinada área da superfície, como a de uma bacia hidrográfica (Rizzi, 2004).

O HAND, desenvolvido por Rennó et al. (2008), é um algoritmo que obtém a descrição do terreno, a partir da diferença de altura entre as regiões testadas e o curso d'água mais próximo. Segundo Pinheiro et al. (2009) agrupa os pixels similares em zonas equiprováveis, considerando seu potencial hidrológico, produzindo mapas com forte significado ecológico e geomorfológico. Esse algoritmo tem sido empregado em vários trabalhos de classificação de solos, revelando forte correlação entre as condições de água no solo, nível do lençol freático e a topografia.

Alguns estudos têm mostrado que a topografia exerce influência sobre a vegetação, uma vez que determina as feições hidrológicas, variações de disponibilidade hídrica, distribuição dos solos e topoclimas (Bispo e Valeriano, 2009). Com o intuito de corroborar no desenvolvimento e compreensão de cenários cujos principais objetivos têm vistas ao planejamento e ordenamento do território, os índices têm sido empregados em vários trabalhos tanto para mapear a vegetação e a condição da mesma, como para corroborar no desenvolvimento e compreensão de cenários com vistas ao planejamento e ordenamento do território.

Sá et al. (2008) utilizaram imagens digitais do satélite TM/Landsat-5 e uma base digital de rodovias da região para determinar a situação atual e a fisionomia, da cobertura vegetal, da região do polo gesseiro do Araripe Pernambucano. Mediante o uso do IVDN, os autores observaram que a região possui aproximadamente $54 \%$ de cobertura vegetal remanescente e cerca de $44 \%$ de áreas antropizadas em diferentes níveis.

Ramos et al. (2010) avaliaram as localidades de áreas degradadas contidos no Parque Nacional Boqueirão da Onça (PNBO)/Bahia, aplicando o IVDN, gerado por meio de imagens do satélite TM/Landsat-5.

Valores do IVDN foram classificados em áreas degradadas, de transição e conservadas, em seguida efetuaram-se comparações entre as cenas, avaliando as áreas para cada classe no interior do parque.

Concluíram que o monitoramento por meio do IVDN, tem sido aperfeiçoado constantemente e se mostrou adequado na avaliação da perda de vegetação nativa no interior e nas bordas do PNBO.

Gong \& Liu (2011) determinaram o IVDN do rio Songhuajiang, na China, para estimar quantitativamente a vegetação, de acordo com a análise e comparação da dinâmica da cobertura vegetal a partir de imagens TM/Landsat-5 de 1989, 1995 e 2001.

Ereno (2010) cita que o HAND foi aplicado na região metropolitana de São Paulo com o 
intuito de avaliar os riscos de inundações e movimentação de massa.

De acordo com este trabalho "As áreas do terreno suscetíveis a enchentes e inundações, identificadas quantitativamente pela primeira vez pela aplicação do método Hand, foram sobrepostas à mancha urbana, tornando possível a visualização das áreas de ocupações mais vulneráveis”.

Pereira et al. (2011) verificaram se há relação entre os valores de HAND e do IVDN, no teor de umidade do solo, em estudo realizado no Parque Nacional de Brasília. Os autores concluíram que o IVDN e o HAND possuem padrões semelhantes, nos quais os valores maiores de IVDN correspondentes a valores menores de HAND.

\section{CARACTERÍSTICAS DA ÁREA DE ESTUDO}

A bacia hidrográfica do rio Gramame está situada microrregião Litorânea Sul Paraibana, entre as latitudes $7^{\circ} 11^{\prime}$ e $7^{\circ} 23^{\prime}$ ' Sul e as longitudes $34^{\circ} 48^{\prime}$ e $35^{\circ} 10^{\prime}$ Oeste.

Possui uma área de 589,1 km² e sua extensão
Nesse estudo verificou-se que os índices indicaram claramente o posicionamento da rede de drenagem e seu entorno mais próximo que podem ser classificados com alto grau de umidade.

Nesta perspectiva, este trabalho teve por objetivo aplicar o IVDN no estudo da degradação ambiental da bacia hidrográfica do rio Gramame, tendo como objetivos específicos o pré-processamento das imagens de satélite; a avaliação da densidade e as alterações da cobertura vegetal, por meio do IVDN; analisar da dinâmica da ocupação do solo nos anos de 1989, 2001 e 2006; e a obtenção do desnível em relação à rede de drenagem, a partir do HAND.

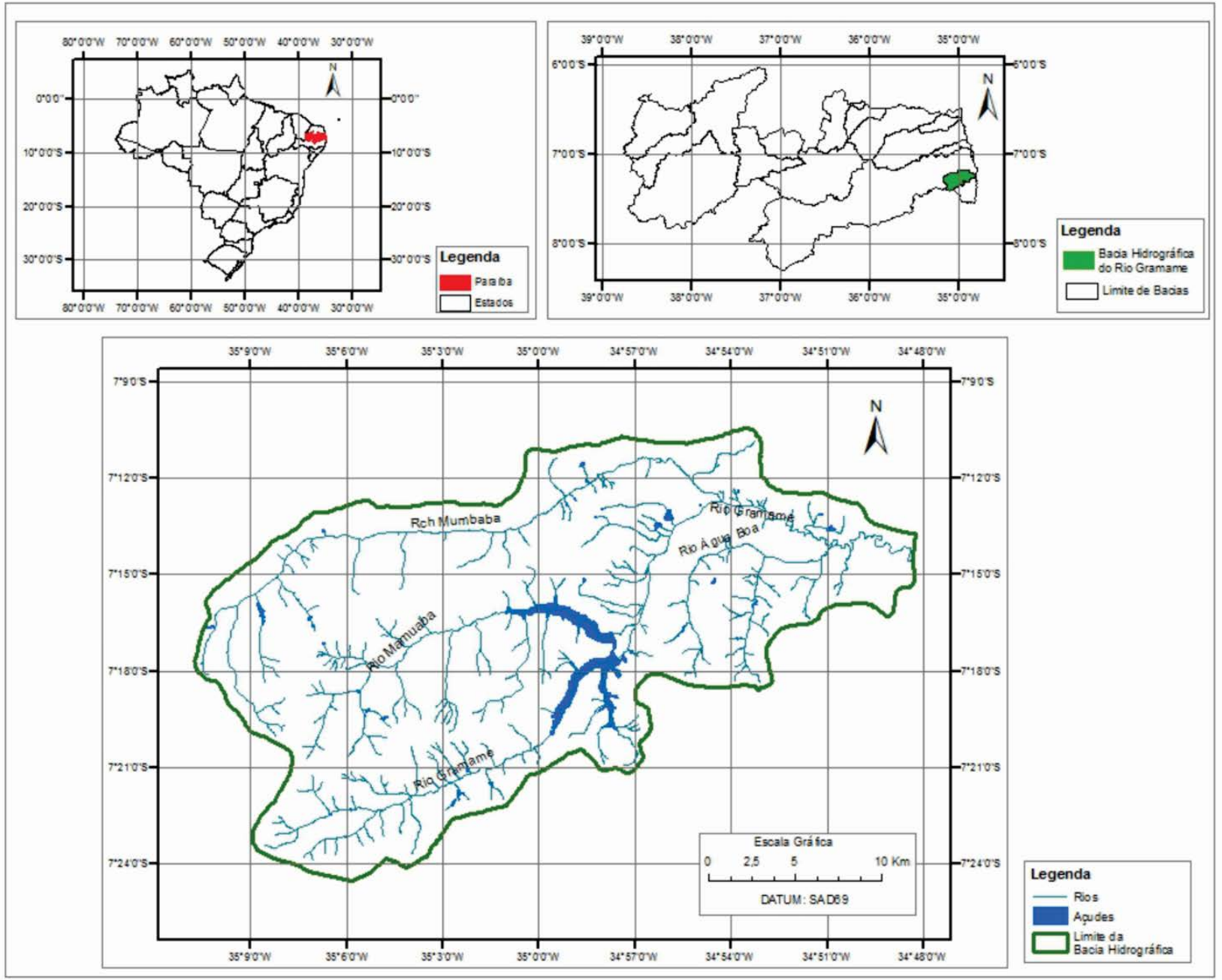

Figura 1 - Localização da bacia hidrográfica do rio Gramame, Paraíba. 
O clima é tropical chuvoso e sua rede hidrográfica é formada, principalmente pelos rios Gramame, Mamuaba, Mumbaba e Água Boa. O rio Gramame é o principal curso d’água da bacia hidrográfica.

Nessa bacia encontra-se o reservatório Gramame-Mamuaba, que contém capacidade de armazenamento de 56 milhões de $\mathrm{m}^{3}$ de água e é responsável por cerca de 70\% do abastecimento de água da grande João Pessoa. A vegetação é composta por matas, manguezais e cerrados, formados por gramíneas e arbustos tortuosos. Segundo Coelho (2011), a bacia vem passando por um processo de desmatamento e ocupação desordenada, existindo apenas $15 \%$ de vegetação densa, mata ciliar e mangue.

\section{MATERIAIS E MÉTODOS}

Este trabalho foi realizado com o uso de imagens orbitais do satélite Landsat 5 , sensor
TM, e do radar da The Shuttle Radar Topography Mission (SRTM) (Tabela 1).

Tabela 1 - Materiais utilizados.

\begin{tabular}{c|c|c|c|c}
\hline MATERIAIS & DATA & ÓRBITA & PONTO & FONTE \\
\hline TM/Landsat-5 & $10 / 07 / 1989$ & 214 & 265 & INPE \\
\hline TM/Landsat-5 & $04 / 08 / 2001$ & 214 & 265 & INPE \\
\hline TM/Landsat-5 & $26 / 08 / 2006$ & 214 & 265 & INPE \\
\hline SRTM & $11 / 02 / 2000$ & - & - & EMBRAPA \\
\hline
\end{tabular}

\section{Pré-Processamento das Imagens de Satélite}

Inicialmente foram realizadas as correções atmosféricas e radiométricas, inerentes aos erros causados pelos efeitos de espalhamento e absorção (Song, 2001), que foram importantes para ajustar o contraste, as formas e a nitidez das imagens.

Para a correção atmosférica foi utilizada a técnica Dark Object Subtraction (DOS), proposta por Chavez (1996), que é baseada em correções atmosféricas absolutas do histograma. Para a correção radiométrica utilizou-se a ferramenta de restauração do software SPRING, para corrigir as distorções inseridas pelo sensor no processo de geração das imagens.

\section{Obtenção do Ivdn}

Foram confeccionadas as imagens de IVDN, a partir da ferramenta especifica existente no SPRING, que utiliza a equação, proposta por Rouse Júnior et al. (1973). Este índice destaca a densidade da cobertura vegetal e apresenta valores que variam de -1 a +1 , estando à vegetação associada aos valores positivos que quanto maiores, maior a biomassa. Nuvens e água apresentam valores negativos, solos descobertos e rochas apresentam valores próximos de zero (Rizzi, 2004).

Em seguida, a imagem de IVDN foi fatiada em seis classes temáticas para possibilitar uma melhor visualização da variação do IVDN e o cruzamento com os demais mapas. Os intervalos estabelecidos foram de -1 a -0,26; -
0,26 a 0,$15 ; 0,15$ a 0,$30 ; 0,30$ a 0,$45 ; 0,45$ a 0,60 ; e 0,60 a 1 .

\section{Atividades de Campo}

As atividades de campo trataram de visitas in loco, com o intuito de identificar as áreas amostrais para o processamento da cobertura e uso do solo da bacia hidrográfica do rio Gramame, bem como para apoiar as análises temporais e entre os parâmetros adotados neste estudo. Foram visitados, georreferenciados e fotografados, 194 locais representativos de vários usos do solo, tais como: áreas urbanas, áreas degradadas, mineração, recursos hídricos, culturas agrícolas, florestais e pastagens. Nesses locais também foram realizadas conversas informais com moradores, para a averiguação temporal daquele uso do solo. A partir das informações obtidas nessas visitas, foram feitas análises comparativas entre as feições das imagens temporais utilizadas neste trabalho (padrão, cor, textura, localização, entre outras) e das informações obtidas nas conversas informais, para avaliar e validar se na época do imageamento aquele local já tinha o uso verificado in loco. Após a validação, foram definidas as tonalidades de cinza a serem adotadas na classificação da cobertura e uso do solo. Essa análise comparativa foi realizada na imagem TM/Landsat-5 do ano de 2006, por estar mais recente em relação ao período da coleta dos dados em campo.

A partir do que foi validado na imagem de 
2006 foram estabelecidos padrões de feições e tonalidades de cinza, para a implementação de regiões amostrais independentes na imagem de 1989. Este mesmo procedimento foi realizado também para a imagem de 2001.

\section{Mapeamento da Cobertura e Uso do Solo}

O mapeamento da cobertura e uso do solo foi realizado utilizando o classificador Batthacharya, proposto por Mather (1999), para realizar uma classificação supervisionada por região, para as seis classes temáticas, adotadas neste trabalho: recursos hídricos, solo exposto/área urbana, vegetação densa, cana-de-açúcar, abacaxi e outros cultivos agrícolas.

O processo de classificação da cobertura e uso do solo, para o ano de 2006, foi realizado utilizando-se regiões amostrais, validadas na imagem, a partir dos dados coletados em campo. Já na classificação da cobertura e uso do solo, para os anos de 1989 e 2001, utilizou-se regiões amostrais validadas a partir das características (padrão, cor, textura, entre outras), observadas na imagem 2006.

\section{Obtenção do Hand}

Esta etapa do trabalho foi realizada a partir das informações topográficas do Modelo Digital de Elevação (MDE), extraídas da imagem SRTM. A partir das informações do MDE foram extraídas as informações sobre a morfologia e a superfície terrestre, por meio do algoritmo HAND, que obtém a descrição do terreno a partir da altura das regiões testadas até a rede de drenagem mais próxima.

A imagem resultante da aplicação do HAND foi fatiada em seis classes temáticas para possibilitar uma melhor visualização dos desníveis e posterior cruzamento com o IVDN. Os intervalos estabelecidos para as seis classes temáticas foram: 0 a 2 metros; 2 a 30 metros; 30 a 55 metros; 55 a 88 metros; 88 a 125 metros; e 125 a 162 metros.

\section{Cruzamentos dos Dados}

Para a realização do cruzamento dos mapas temáticos do IVDN com os de cobertura e uso do solo e do HAND, foram realizadas novas classificações de cada mapa temático, as quais estão apresentadas na figura 2 .

\begin{tabular}{|c|c|c|c|}
\hline CLASSE & IVDN & COBERTURA E USO DO SOLO & HAND \\
\hline 1 & -1 a $-0,25$ & Recursos hídricos & 0 a 2 metros \\
\hline 2 & $-0,25$ a 0,15 & Solo exposto/área urbana & 2 a 37 metros \\
\hline 3 & 0,15 a 0,45 & Cultivos & 37 a 72 metros \\
\hline 4 & 0,45 a 0,60 & Cana-de-açúcar & 72 a 107 metros \\
\hline 5 & 0,60 a 1 & Vegetação densa & 107 a 150 metros \\
\hline
\end{tabular}

Figura 2 - Classes de IVDN, Cobertura e uso do Solo e HAND.

\section{RESULTADOS E DISCUSSÕES}

\section{Resposta do Ivdn}

A figura 3 apresenta os valores obtidos do IVDN para a bacia hidrográfica do rio Gramame, para o ano de 1989. Observa-se pela figura 3 que houve uma grande representatividade da categoria de intervalo 0,6 a 1 (58\% da área da bacia hidrográfica), que caracteriza a vegetação com maior biomassa.

Por outro lado, o intervalo de 0,30 a 0,45 (11\% da área da bacia hidrográfica), juntamente com o intervalo 0,15 a 0,30 (6\% da área da bacia hidrográfica), podem caracterizar o total de áreas degradadas, para este ano de 1989 (figura 4).

Pela figura 5 observa-se que houve uma diminuição das áreas de intervalo 0,60 a 1 , quando comparado com o ano de 1989. Nesse ano de 2001 este intervalo representou apenas $32 \%$ da área da bacia, com uma queda de 44,83\% em relação ao IVDN do ano de 1989.

Esta queda no percentual de área com maior biomassa pode ter sido ocasionada pelo forte período de seca, no qual o estado da Paraíba vinha passando devido aos fortes eventos El Niño-Oscilação do Sul (ENOS), ocorridos em 1991-1992 e 1997-1998. Segundo Paraíba (2000a) esse período de seca pôs em risco de colapso a disponibilidade hídrica da bacia hidrográfica do rio Gramame.

Com a diminuição das áreas do intervalo 
0,60 a 1 , observa-se também que houve um aumento de $183,33 \%$ na categoria de intervalo $-0,26$ a 0,15 e de $100 \%$ na de intervalo 0,15 a 0,30, o que pode indicar uma maior degradação da área da bacia hidrográfica.

No entanto, isto pode estar relacionado com o período de seca, que ocasionou a proibição do uso da água da bacia hidrográfica, para a irrigação, a partir do ano 2000.

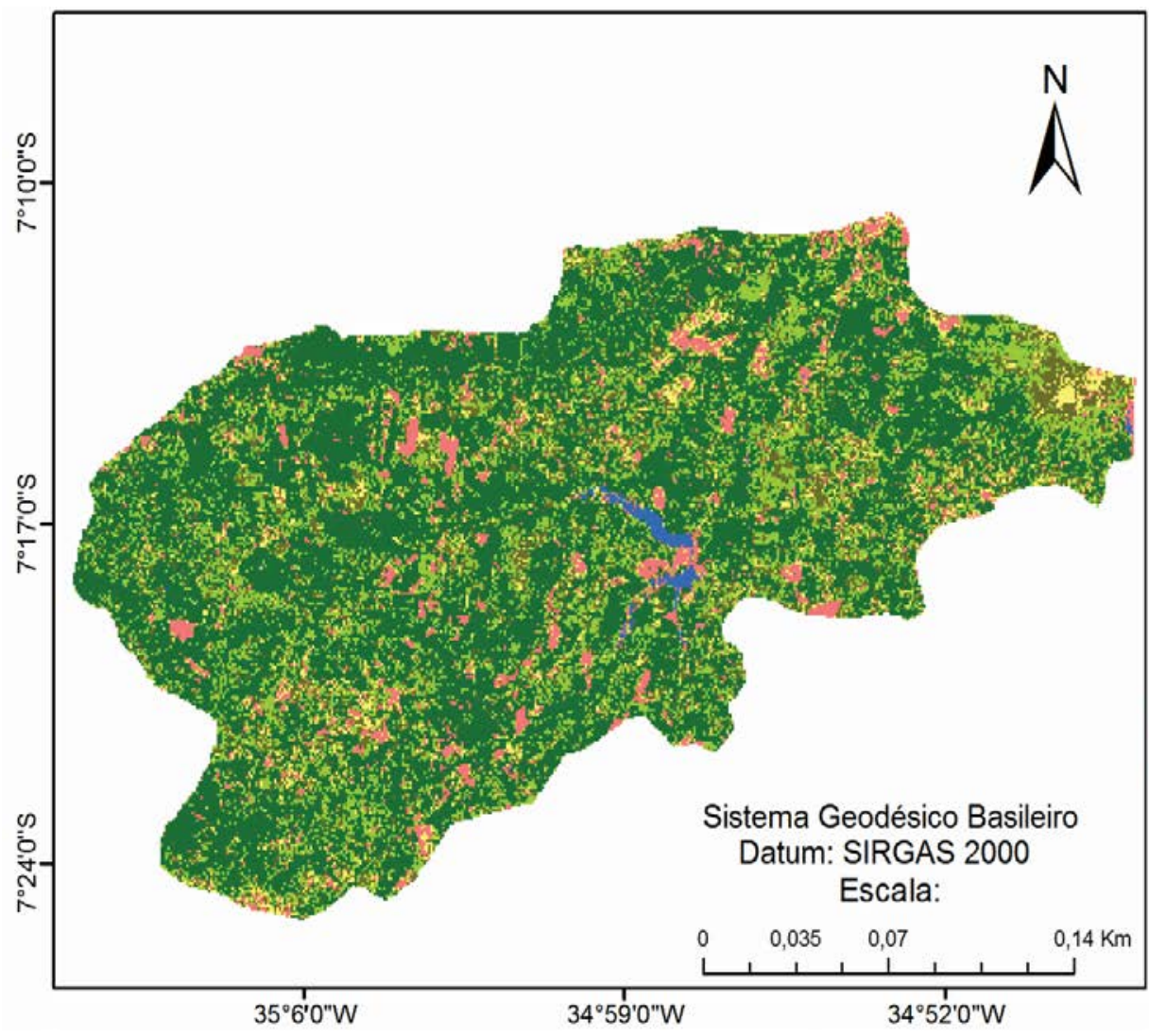

Legenda:

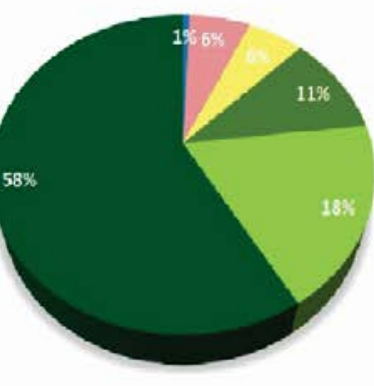

Figura 3 - IVDN da bacia hidrográfica do rio Gramame 1989.

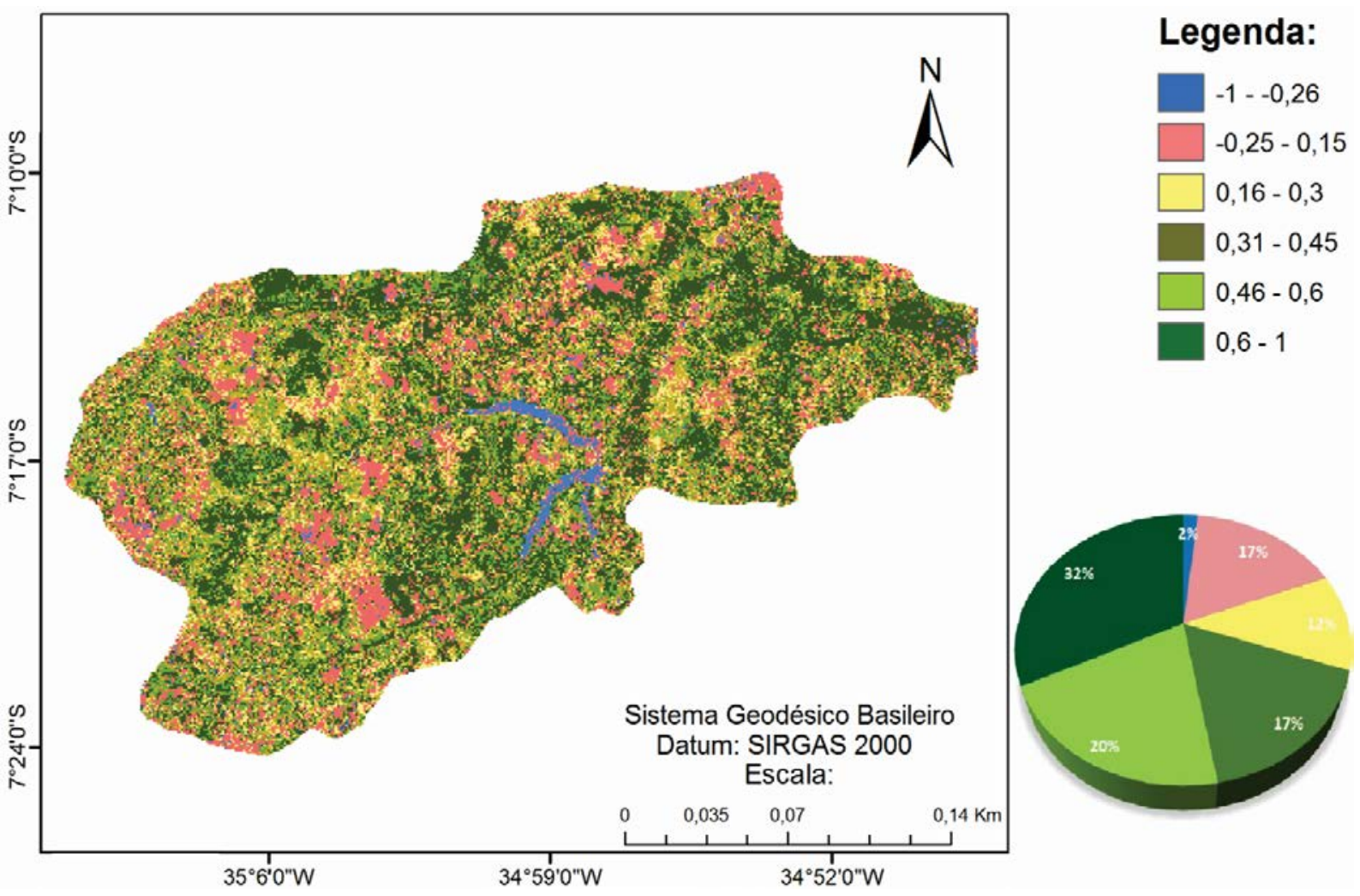

Figura 4 - IVDN da bacia hidrográfica do rio Gramame 2001. 
O acréscimo de $100 \%$ verificado na categoria de intervalo -1 a -0,26 de 1989 para 2001 pode estar relacionado: com a proibição do uso da água da bacia hidrográfica do rio
Gramame para a irrigação; pela retomada das chuvas; ou devido a algum erro no préprocessamento e/ou na classificação da imagem.

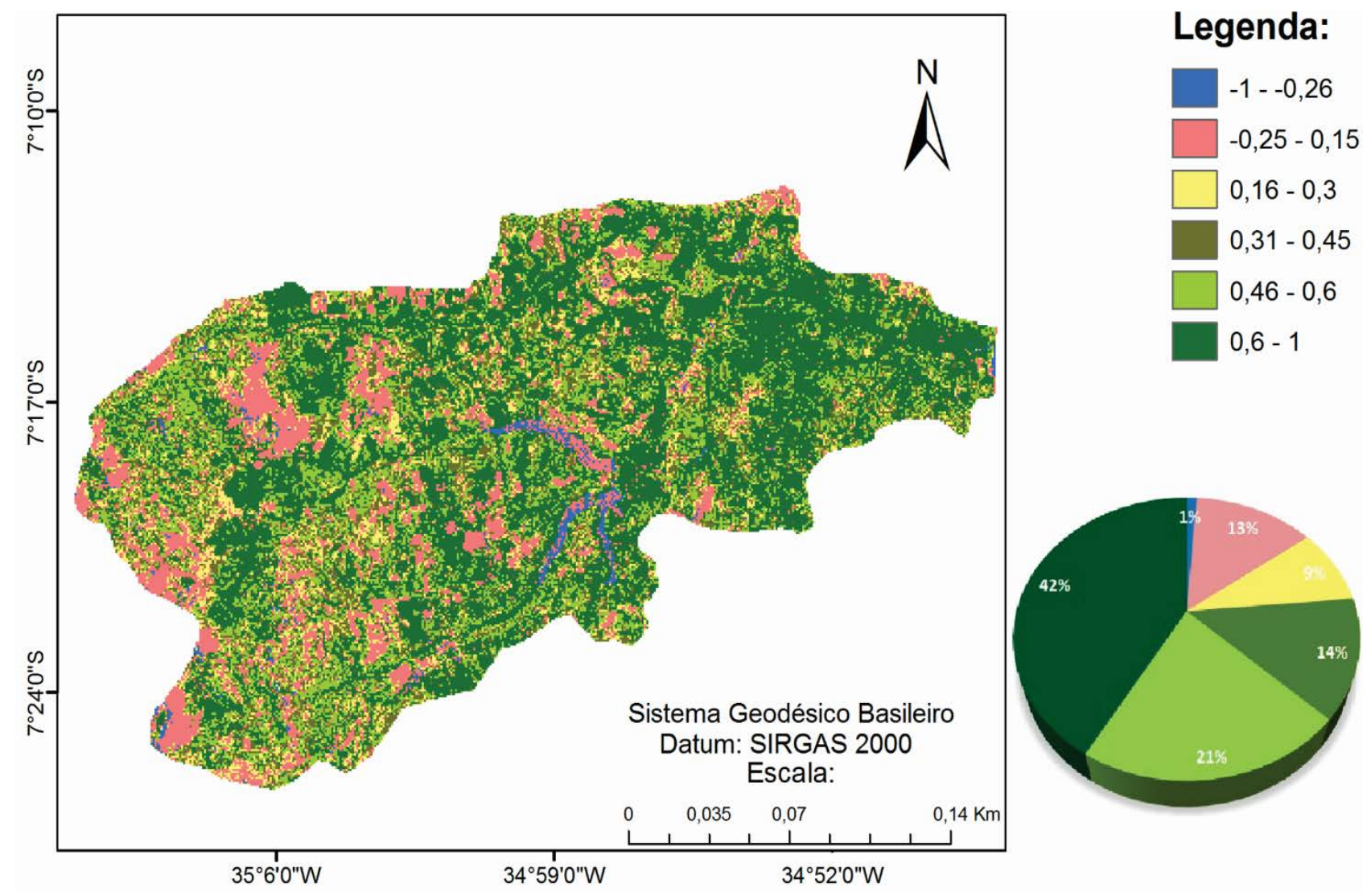

Legenda:

Figura 5 - IVDN da bacia hidrográfica do rio Gramame 2006.

O IVDN da bacia hidrográfica do Gramame, extraído da imagem do ano de 2006 (Figura 5), apontou um aumento de $31,25 \%$ das áreas que representam o intervalo de 0,60 a 1 em relação aos dados de 2001. Porém, não chegando ao patamar inicial no qual representava mais da metade da área da bacia, verificado pelos dados do IVDN da imagem de 1989. Comparando com o ano de 2001, houve uma diminuição de $23,53 \%$ para o intervalo $-0,26$ a 0,15 e de $25 \%$ para o intervalo 0,15 a 0,30 , o que pode representar uma diminuição de áreas degradadas para este ano de 2006. Já as áreas de intervalo 0,45 a 0,60 aumentaram $5 \%$, enquanto as áreas de intervalo 0,30 a 0,45 diminuíram $17,65 \%$. Isto pode ser justificado pela diminuição no cultivo das chamadas "culturas brancas" (batata doce, batata inglesa, mandioca e inhame), muito comum em pequenas propriedades da região, para dar lugar à cultura da cana-de-açúcar, a qual predomina na bacia.

Fazendo-se uma análise multitemporal sintética, dos dados dos valores obtidos no
IVDN, apresentados nas Figuras 3, 4 e 5 observa-se que para a bacia hidrográfica do rio Gramame houve uma diminuição das áreas que representam a vegetação mais vigorosa e um aumento das categorias com baixo IVDN, de 1989 para 2001. Posteriormente observa-se a situação inversa, apresentando um aumento das áreas representantes de vegetação com valores de IVDN altos e diminuição das categorias com IVDN próximos de zero, de 2001 para 2006.

Essas alterações podem indicar uma degradação no primeiro período (1989-2001) e uma recuperação no segundo período (20012006) fato que aumenta os indícios de que a queda nas áreas de vegetação mais vigorosa e aumento das categorias com valores próximos de zero, que podem representar áreas degradadas, verificados no ano de 2001, foi ocasionado pela forte seca ocorrida na região ou pela proibição do uso da água da bacia hidrográfica para a irrigação a partir do ano 2000, devido ao racionamento de água, que também é consequência da seca. 


\section{Cobertura e Uso do Solo}

Nas figuras 6, 7, 8 estão apresentados os mapas temáticos temporais de cobertura e uso do solo, da bacia hidrográfica do rio Gramame, para as seis categorias estudadas, para os anos de 1989, 2001 e 2006.

Analisando a figura 6 verifica-se que a cultura de cana-de-açúcar teve a maior presença com $44 \%$ da área total da bacia hidrográfica, seguida das áreas de vegetação densa com $28 \%$ de representação. Já a categoria solo exposto/área urbana teve a terceira maior representatividade, com $17 \%$ da área da bacia hidrográfica.

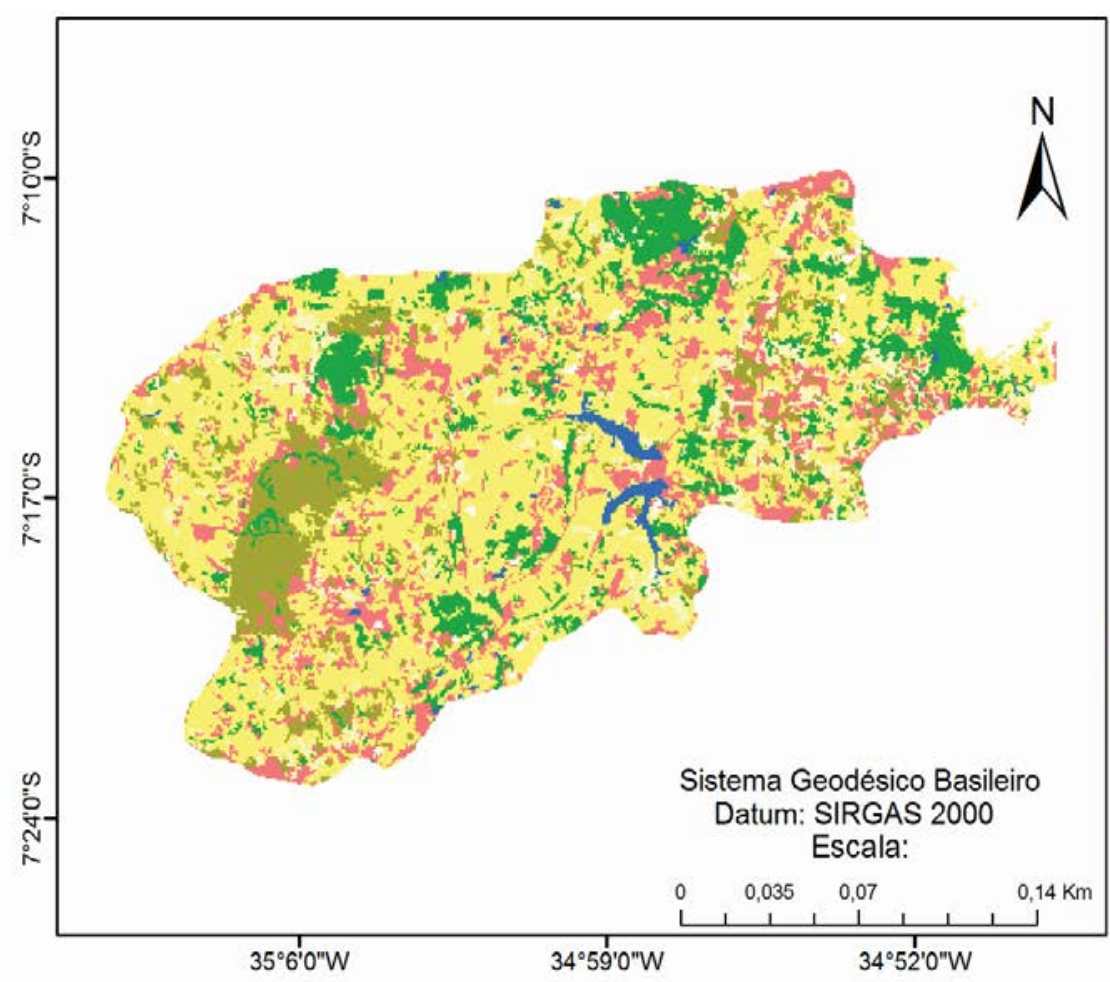

\section{Legenda:}

Recursos Hídricos

Solo Exposto/Área Urbana

Vegetação Densa

$\square$ Cana-de-Açucar

$\square$ Abacaxi

Cultivos

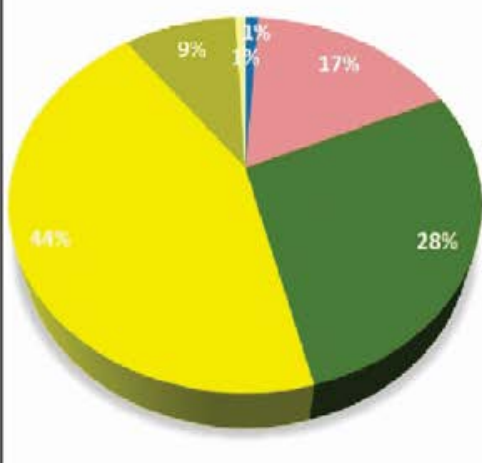

Figura 6 - Cobertura e uso do solo da bacia hidrográfica do rio Gramame 1989.

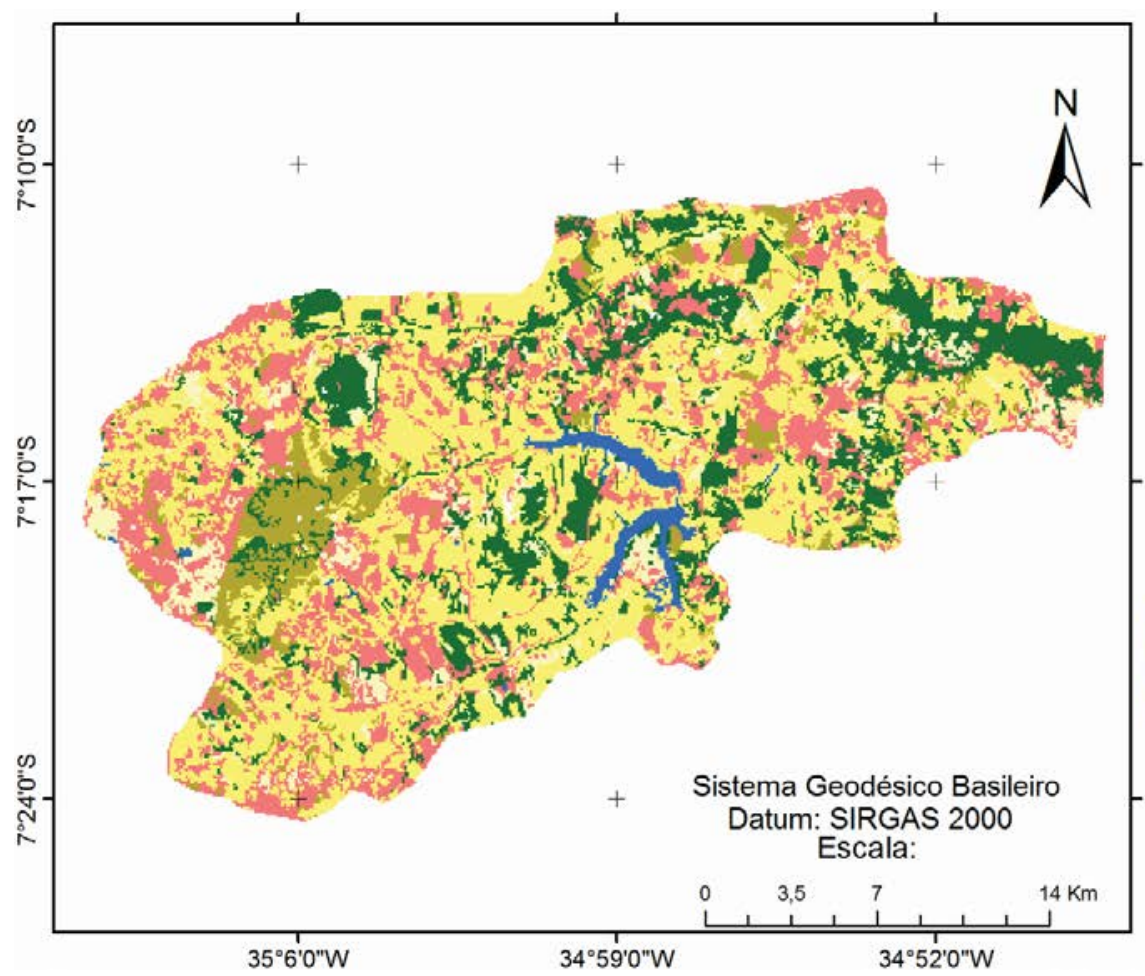

\section{Legenda:}

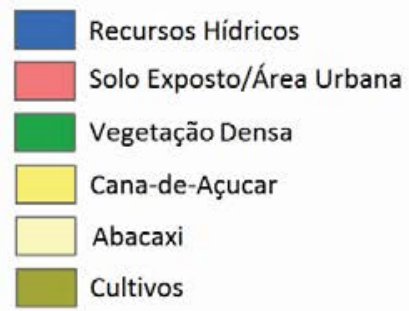

Figura 7 - Cobertura e uso do solo da bacia hidrográfica do rio Gramame 2001. 
A figura 7 mostra que, assim como foi observado nos resultados do IVDN para esta bacia hidrográfica, houve uma queda nas áreas de vegetação densa, passando de 28\% em 1989 para $19 \%$ em 2001, totalizando uma queda de $32,14 \%$ entre esses anos. Apesar de ter sido constatada essa queda nas áreas de vegetação densa, houve um aumento nas áreas ocupadas por cana-de-açúcar, abacaxi e de recursos hídricos superficiais.

Comparando o resultado da figura $8 \mathrm{com}$ os apresentados para o ano de 2001, pode ser observado que houve um ganho de $47,37 \%$ da área da bacia hidrográfica na categoria vegetação densa. Esta alteração também foi observada nos resultados do IVDN para o mesmo período.

Porém, no resultado da cobertura e uso do solo as áreas que diminuíram foram aquelas com os cultivos de cana-de-açúcar e abacaxi, que reduziram sua representação em 8,51\% e
83,33\%, respectivamente.

Estes dados apontam novamente para a hipótese de que os resultados obtidos a partir da imagem de 2001 apresentaram as consequências do período de seca, ocorrido em anos anteriores.

No entanto, no período de 2001 a 2006 verifica-se uma regeneração da vegetação densa, provavelmente devido a retomada das chuvas, o que pode explicar o aumento do percentual desta categoria nesse período.

\section{Resposta do Hand}

Na figura 9 está apresentado o resultado do processamento do HAND para a bacia hidrográfica do rio Gramame, para as seis categorias estabelecidas.

Estes dados permitiram o cruzamento das informações com as dos mapas de IVDN, o que possibilitou a realização de análises comparativas mais detalhadas, permitindo justificar algumas respostas do IVDN.

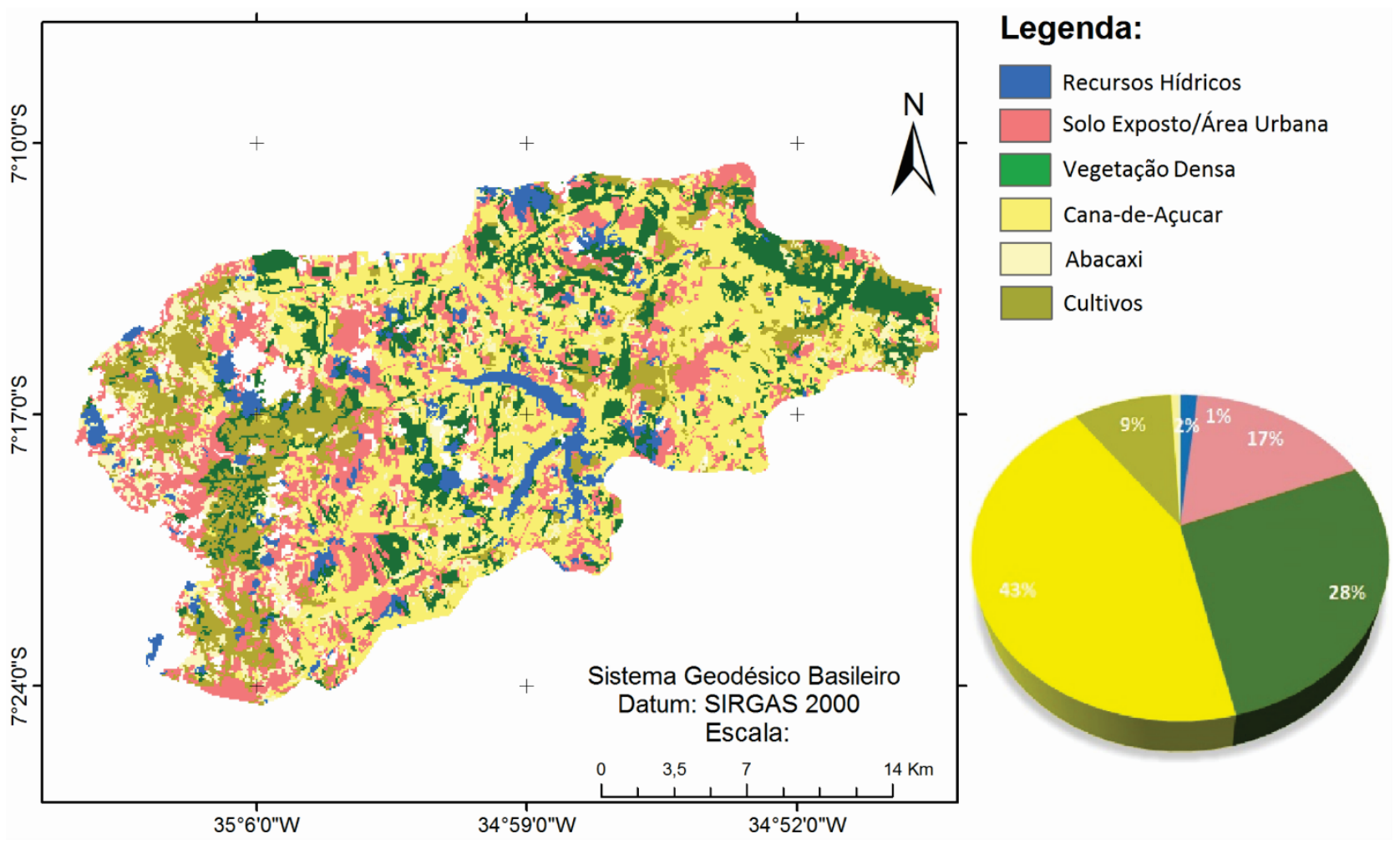

Figura 8 - Cobertura e uso do solo da bacia hidrográfica do rio Gramame 2006.

A partir da análise da figura 9 pode-se verificar que a maior parte da bacia hidrográfica do rio Gramame apresenta desníveis variando de 30m a 55m em relação à rede de drenagem mais próxima. Isto representa 31\% da área total da bacia hidrográfica. Esses desníveis predominam em quase toda a subbacia hidrográfica do rio Mumbaba e no entorno do reservatório Gramame-Mamuaba.

A segunda categoria mais representativa no HAND é a que apresenta desníveis variando de $2 \mathrm{~m}$ a $30 \mathrm{~m}$ em relação à rede de drenagem, (29\% da área da bacia hidrográfica). A predominância dessa categoria ocorre nas áreas que contém matas ciliares. Outra classe de destaque na bacia hidrográfica são as regiões 
com desníveis de $55 \mathrm{~m}$ a $88 \mathrm{~m}$, que representam 23\% da área da bacia hidrográfica do rio Gramame. Essa categoria predomina nas regiões medianas da bacia hidrográfica, a montante do reservatório Gramame-Mamuaba e no alto curso do rio Água Boa.

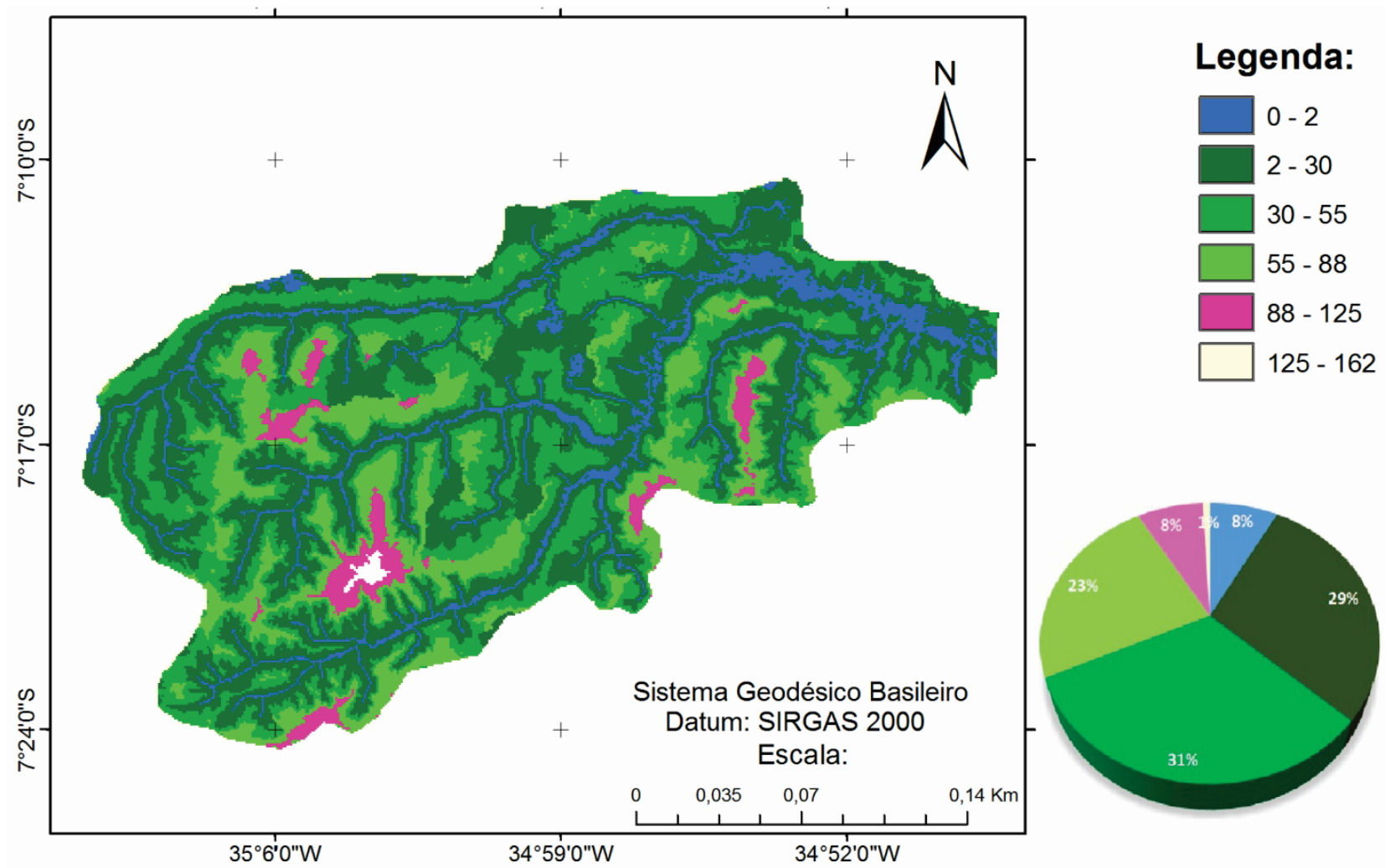

Figura 9 - Mapa do HAND da bacia hidrográfica do rio Gramame.

As áreas mais baixas, de 0 a $2 \mathrm{~m}$ e as regiões altas, com desnível de $88 \mathrm{~m}$ a $125 \mathrm{~m}$, representam $8 \%$ da área total da bacia hidrográfica do rio Gramame. As áreas mais altas estão situadas na região mediana da bacia, localizada entre os rios Mamuaba e Gramame. Já as áreas com maior diferença de nível em relação à rede de drenagem mais próxima, de $125 \mathrm{~m}$ a $162 \mathrm{~m}$ de desnível, representam apenas $1 \%$ do total da bacia hidrográfica.

\section{Cruzamento entre o Ivdn e a Cobertura e Uso do Solo}

O cruzamento do IVDN com a cobertura e uso do solo objetivou avaliar a interferência dos diferentes usos do solo nas repostas do IVDN e verificar se houve alguma distorção dos alvos nos processamentos. Para que esse cruzamento podessse ser realizado foi inserida uma nova classe para todos os mapas temáticos envolvidos no procedimento. Essa nova classe, denominada de classe 0 , representa a área externa do retângulo envolvente da bacia hidrográfica, além de núvens e ruídos presentes nas imagens TM/Landsat-5.

Na figura 10 são apresentados os dados do cruzamento dos mapas temáticos do IVDN e de cobertura e uso do solo para a bacia hidrográfica do rio Gramame no ano de 1989.

\begin{tabular}{|c|c|c|c|c|c|c|c|}
\hline \multirow{2}{*}{ Cobertura e uso do solo } & \multicolumn{6}{|c|}{ IVDN } & \multirow{2}{*}{ Uso Solo (\%) } \\
\hline & $\mathbf{0}$ & 1 & 2 & 3 & 4 & 5 & \\
\hline 0 & 45,11 & 0,0 & 0,15 & 0,80 & 0,28 & 0,04 & 46,38 \\
\hline Recursos hídricos & 0,00 & 0,25 & 0,12 & 0,10 & 0,06 & 0,16 & 0,69 \\
\hline Solo exposto/ Área urbana & 0,01 & 0,02 & 2,48 & 4,29 & 1,38 & 0,26 & 8,44 \\
\hline Cultivos & 0,02 & 0,00 & 0,07 & 1,83 & 3,56 & 4,25 & 9,73 \\
\hline Cana-de-açúcar & 0,01 & 0,02 & 0,10 & 1,76 & 5,43 & 20,02 & 27,34 \\
\hline Vegetação densa & 0,00 & 0,00 & 0,28 & 0,10 & 0,33 & 6,71 & 7,42 \\
\hline IVDN (\%) & 45,15 & 0,29 & 3,20 & 8,88 & 11,04 & 31,44 & 100,00 \\
\hline
\end{tabular}

Figura 10 - Tabulação cruzada proporcional do IVDN com a cobertura e uso do solo da bacia hidrográfica do Gramame, no ano de 1989. 
Analisando o quadro acima verifica-se que a percentagem da classe 0 do IVDN é praticamente a mesma classe 0 de cobertura e uso do solo. Isto mostra que a parte externa dos mapas temáticos e as falhas que permaneceram após as correções, coincidiu quase totalmente.

Para a classe 1 , dos $0,29 \%$ de representação no IVDN, 0,25\% coincidiram com a classe recursos hídricos na cobertura e uso do solo. Já a classe 2, de 3,20\% do IVDN, 2,48\% coincidiram com solo exposto/área urbana na cobertura e uso do solo.

Comparando os valores percentuais para a categoria que se refere às áreas de cultivos (pastos, "culturas brancas", abacaxi, bambu e os demais cultivos de pequenas propriedades), verifica-se que houve uma incoerência entre os mapas temáticos de IVDN e de cobertura e uso do solo.

Para o IVDN, na classe 3, observou-se uma coincidência de 4,29\% com a categoria solo exposto/área urbana, enquanto apenas 1,83\% coincidiram com a categoria cultivos no mapa de cobertura e uso do solo. Isso pode ter ocorrido porque os pastos podem ser confundidos com solo exposto, como também, por causa da existência de variados tipos de culturas, que podem ser de pequeno porte. Também aos vários estádios de desenvolvimento vegetativo que podem se encontrar a vegetação na época do imageamento.

Houve certa incoerência dos percentuais do IVDN e de cobertura e uso do solo para as classes 4 e 5 . Do total de 11,04\% no IVDN para a classe 4 , o maior valor foi para a cana-deaçúcar, o que de certa forma está coerente. No entanto, o maior valor do IVDN para a classe 5 também foi para a cana-de-açúcar e não para a vegetação densa.

Isto pode ter ocorrido devido ao limite adotado no processamento do IVDN para as classes 4 e 5 , fazendo com que os percentuais totais não ficassem próximos dos obtidos para a cobertura e uso do solo nas categorias cana-deaçúcar e vegetação densa.

A figura 11 apresenta os dados de cruzamento entre os mapas temáticos do IVDN e de cobertura e uso do solo para a bacia hidrográfica do rio Gramame no ano de 2001.

\begin{tabular}{|c|c|c|c|c|c|c|c|}
\hline \multirow{2}{*}{ Cobertura e uso do solo } & \multicolumn{6}{|c|}{ IVDN } & \multirow{2}{*}{ Uso Solo (\%) } \\
\hline & $\mathbf{0}$ & 1 & 2 & 3 & 4 & 5 & \\
\hline 0 & 45,11 & 0,01 & 0,08 & 0,07 & 0,02 & 0,02 & 45,31 \\
\hline Recursos hídricos & 0,00 & 0,48 & 0,21 & 0,06 & 0,03 & 0,15 & 0,93 \\
\hline Solo exposto/ Área urbana & 0,01 & 0,35 & 6,53 & 4,48 & 0,67 & 0,25 & 12,29 \\
\hline Cultivos & 0,01 & 0,01 & 0,55 & 3,30 & 2,12 & 1,24 & 7,23 \\
\hline Cana-de-açúcar & 0,01 & 0,05 & 1,15 & 7,10 & 7,39 & 8,43 & 24,13 \\
\hline Vegetação densa & 0,00 & 0,03 & 0,88 & 0,59 & 0,96 & 7,65 & 10,11 \\
\hline IVDN (\%) & 45,14 & 0,93 & 9,40 & 15,60 & 11,19 & 17,74 & 100,00 \\
\hline
\end{tabular}

Figura 11 - Tabulação cruzada proporcional do IVDN com a cobertura e uso do solo da bacia hidrográfica do Gramame, no ano de 2001.

A classe 1 do IVDN, apresentou maior coincidência com a classe recursos hídricos da cobertura e uso do solo, sendo 0,48\% de um total de $0,93 \%$. Já a classe 2 de 9,40\% do IVDN, 6,53\% coincidiram com a classe solo exposto/área urbana da cobertura e uso do solo.

A classe 3 do IVDN, de um total de 15,60\%, apresentou $7,10 \%$ de coincidência com a classe de cana-de-açúcar, 4,48\% com solo exposto/área urbana e apenas 3,30\% identificaram-se com os cultivos da cobertura e uso do solo. Este fato pode ter ocorrido, devido à existência de diversos tipos de culturas, que podem estar em vários estágios fenológicos, causando uma indistinção de alguns cultivos com a cana-de-açúcar ou com o solo exposto.

A classe 4 do IVDN, com total de 11,19\%, apontou 7,39\% de coincidência com a classe de cana-de-açúcar da cobertura e uso do solo. Já a classe 5 apontou novamente maior coincidência com a classe de cana-de-açúcar 8,43\%, enquanto para a classe de vegetação densa foi de 7,65\%. Este fato demonstra que ainda existe uma incoerência, no entanto em uma proporção bem menor do que a apresentada para o ano de 1989. 
A figura 12 apresenta os dados de e de cobertura e uso do solo para a bacia cruzamento entre os mapas temáticos do IVDN hidrográfica do rio Gramame no ano de 2006.

\begin{tabular}{|c|c|c|c|c|c|c|c|}
\hline \multirow{2}{*}{ Cobertura e uso do solo } & \multicolumn{6}{|c|}{ IVDN } & \multirow{2}{*}{ Uso Solo (\%) } \\
\hline & 0 & 1 & 2 & 3 & 4 & 5 & \\
\hline 0 & 45,12 & 0,13 & 2,39 & 0,48 & 0,06 & 0,03 & 48,21 \\
\hline Recursos hídricos & 0,00 & 0,26 & 0,65 & 0,85 & 0,52 & 0,95 & 3,23 \\
\hline Solo exposto/ Área urbana & 0,01 & 0,10 & 3,91 & 5,84 & 0,91 & 0,11 & 10,88 \\
\hline Cultivos & 0,01 & 0,03 & 0,18 & 3,30 & 4,58 & 3,16 & 11,26 \\
\hline Cana-de-açúcar & 0,00 & 0,07 & 0,12 & 1,73 & 5,21 & 11,05 & 18,18 \\
\hline Vegetação densa & 0,00 & 0,02 & 0,10 & 0,11 & 0,33 & 7,68 & 8,24 \\
\hline IVDN (\%) & 45,14 & 0,61 & 7,35 & 12,31 & 11,61 & 22,98 & 100,00 \\
\hline
\end{tabular}

Figura 12 - Tabulação cruzada proporcional do IVDN com a cobertura e uso do solo da bacia hidrográfica do Gramame, no ano de 2006.

A classe 1 do IVDN, do total de em 0,61\% coincidiu em $0,26 \%$ com a classe recursos hídricos da cobertura e uso do solo e a classe 2 do IVDN, coincidiu em 3,91\% com solo exposto/área urbana da cobertura e uso do solo, de um total de 7,35\%, no ano de 2006.

As classes 1 e 2 coincidiram em 0,13 e $2,39 \%$ com a classe 0 da cobertura e uso do solo, o que pode ter sido ocasionado pela presença de nuvens e/ou sombras, que no IVDN tenham sido inseridas nas classes 1 e 2, e na cobertura e uso do solo, na classe 0 .

Já a classe 3 do IVDN, teve maior coincidência com as classes solo exposto/área urbana, 5,84\% e cultivos, $3,30 \%$ do total de $12,31 \%$. Este erro pode ter ocorrido novamente devido as áreas de pasto e/ou pelos vários tipos de plantações existentes na área de estudo, sejam estas de pequeno ou grande porte e que podem se encontrar em vários estágios fenológicos.

A classe 4 do IVDN novamente apresentaram maior coincidência com a classe cana-de-açúcar, no mapa de cobertura e uso do solo, com 5,21\% de um total de 11,61\%.

Para a classe 5 do IVDN, observa-se que assim como ocorreu nos cruzamentos anteriores, apresentou maior coincidência com as áreas de cana-de-açúcar, com 11,05\%, porém também coincidiu com a vegetação densa do mapa de cobertura e uso do solo, sendo de $7,68 \%$ em 22,98\%, aumentando com isso a disparidade de coincidência entre as classes, em relação a análise de 2001, porém ainda bem menor que a diferença observada no Quadro 1.

As distorções verificadas na classe 3 podem ter ocorrido porque: as áreas de pasto podem ser confundias com solo exposto; os diversos tipos de vegetação existentes na área de estudo, de vários portes e biomassa diferente; e/ou os vários estádios de desenvolvimento vegetativo que podem se encontrar.

No entanto estes erros podem também ser inerentes à presença de nuvens/sombras; e/ou ao processamento, devido aos limites adotados para as classes.

Já os erros observados nas classes 4 e 5, podem ser oriundos da maior representatividade da classe 5, em relação a classe 4, nos mapas de IVDN, e a situação inversa nos mapas de cobertura e uso do solo no qual a cana-deaçúcar que teve maior presença do que a vegetação densa.

Este fato causou mais sobreposição da classe vegetação densa do IVDN com a de cana-deaçúcar na cobertura e uso do solo e provavelmente foi ocasionado devido aos limites adotados para os alvos no processamento do IVDN.

No entanto, esses limites seguiram a bibliografia que associa 0,80 a vegetação vigorosa e com grande quantidade de biomassa (Ponzoni \& Shimabukuro, 2007) e (Silva et al., 2007).

\section{Cruzamento entre o Ivdn e o Hand}

O cruzamento, realizado com os resultados do IVDN e do HAND, da bacia hidrográfica do rio Gramame, objetivou avaliar a influência da proximidade da vegetação com a rede de drenagem, na reposta ao IVDN.

Na figura 13 são apresentados os dados do cruzamento entre os mapas do IVDN e do HAND para a bacia hidrográfica do rio Gramame no ano de 1989. 


\begin{tabular}{|c|c|c|c|c|c|c|c|}
\hline \multirow{2}{*}{ HAND } & \multicolumn{6}{|c|}{ IVDN } & \multirow{2}{*}{$\begin{array}{c}\text { HAND } \\
(\%)\end{array}$} \\
\hline & 0 & 1 & 2 & 3 & 4 & 5 & \\
\hline 0 & 44,75 & 0,01 & 0,04 & 0,07 & 0,06 & 0,12 & 45,05 \\
\hline 1 & 0,38 & 0,23 & 0,20 & 0,60 & 0,80 & 3,05 & 5,26 \\
\hline 2 & 0,00 & 0,08 & 1,51 & 3,98 & 5,30 & 16,28 & 27,14 \\
\hline 3 & 0,00 & 0,00 & 1,07 & 3,15 & 3,81 & 9,75 & 17,78 \\
\hline 4 & 0,00 & 0,00 & 0,32 & 0,96 & 0,97 & 2,04 & 4,29 \\
\hline 5 & 0,00 & 0,00 & 0,05 & 0,12 & 0,11 & 0,19 & 0,47 \\
\hline IVDN (\%) & 45,14 & 0,31 & 3,19 & 8,88 & 11,05 & 31,43 & 100,00 \\
\hline
\end{tabular}

Figura 13 - Tabulação cruzada proporcional do IVDN com HAND da bacia hidrográfica do rio Gramame, no ano de 1989.

No cruzamento dos dados do IVDN da bacia hidrográfica do rio Gramame no ano de 1989 com o HAND da mesma bacia hidrográfica, observa-se que a classe 1 do IVDN está presente, quase totalmente nas áreas com desnível de 0 a $2 \mathrm{~m}$, classe 1 do HAND, ou seja, nas áreas que provavelmente representam rede de drenagem. De um total de 5,26\% da classe 1 do HAND, que representa as áreas com desnível 0 a 2m, 3,05\% coincidiram com a classe 5 do IVDN, que possivelmente representa a mata ciliar. As demais classes do IVDN estão mais presentes nas classes 2 e 3 do HAND, que representam regiões com desnível entre $2 \mathrm{~m}$ e $72 \mathrm{~m}$, principalmente devido a 81,78\% da bacia hidrográfica do rio Gramame apresentar esses desníveis.

A figura 14 apresenta os dados de cruzamento entre os mapas temáticos do IVDN e do HAND para a bacia hidrográfica do rio Gramame no ano de 2001.

\begin{tabular}{|c|c|c|c|c|c|c|c|}
\hline \multirow{2}{*}{ HAND } & \multicolumn{6}{|c|}{ IVDN } & \multirow{2}{*}{$\begin{array}{c}\text { HAND } \\
\text { (\%) }\end{array}$} \\
\hline & 0 & 1 & 2 & 3 & 4 & 5 & \\
\hline 0 & 44,75 & 0,00 & 0,07 & 0,12 & 0,05 & 0,06 & 45,05 \\
\hline 1 & 0,38 & 0,35 & 0,51 & 0,94 & 0,94 & 2,13 & 5,25 \\
\hline 2 & 0,00 & 0,41 & 4,24 & 7,20 & 5,82 & 9,47 & 27,14 \\
\hline 3 & 0,00 & 0,14 & 3,53 & 5,50 & 3,52 & 5,10 & 17,79 \\
\hline 4 & 0,00 & 0,03 & 0,92 & 1,62 & 0,80 & 0,93 & 4,30 \\
\hline 5 & 0,00 & 0,00 & 0,13 & 0,22 & 0,07 & 0,05 & 0,47 \\
\hline IVDN (\%) & 45,13 & 0,93 & 9,40 & 15,60 & 11,20 & 17,74 & 100,00 \\
\hline
\end{tabular}

Figura 14 - Tabulação cruzada proporcional do IVDN com HAND da bacia hidrográfica do rio Gramame, no ano de 2001.

Para o ano de 2001, observa-se que a maior parte da classe 1 do IVDN estava localizada nas regiões representadas pelas classes de 1 a 3 do HAND, com a maior parte na classe 2. Esse fato pode ter ocorrido porque neste ano a vegetação não estava tão exuberante, fazendo com que as áreas de vegetação densa fossem distribuídas em todas as outras classes que foram sobrepostas ao HAND. Em geral as categorias do IVDN tiveram a maior proporção de coincidência com a classe 2 do HAND.

A figura 15 apresenta os dados do cruzamento entre os mapas temáticos do IVDN e do HAND para a bacia hidrográfica do rio Gramame no ano de 2006.

\begin{tabular}{|c|c|c|c|c|c|c|c|}
\hline \multirow{2}{*}{ HAND } & \multicolumn{6}{|c|}{ IVDN } & \multirow{2}{*}{$\begin{array}{c}\text { HAND } \\
(\%)\end{array}$} \\
\hline & 0 & 1 & 2 & 3 & 4 & 5 & \\
\hline 0 & 44,75 & 0,00 & 0,03 & 0,10 & 0,07 & 0,09 & 45,03 \\
\hline 1 & 0,38 & 0,14 & 0,38 & 0,51 & 0,78 & 3,07 & 5,26 \\
\hline 2 & 0,00 & 0,34 & 3,18 & 5,47 & 5,98 & 12,18 & 27,15 \\
\hline 3 & 0,00 & 0,10 & 2,83 & 4,78 & 3,73 & 6,36 & 17,80 \\
\hline 4 & 0,00 & 0,03 & 0,84 & 1,30 & 0,95 & 1,17 & 4,29 \\
\hline 5 & 0,00 & 0,00 & 0,09 & 0,16 & 0,10 & 0,12 & 0,47 \\
\hline IVDN (\%) & 45,13 & 0,61 & 7,35 & 12,32 & 11,61 & 22,98 & 100,00 \\
\hline
\end{tabular}

Figura 15 - Tabulação cruzada proporcional do IVDN com HAND da bacia hidrográfica do rio Gramame, no ano de 2006. 
Comparando as figuras 14 e 15, percebe-se que novamente a classe 1 do IVDN apresentase nas regiões com desnível de 0 a $72 \mathrm{~m}$, com maior presença na classe 2 do HAND, coincidindo $0,34 \%$ do total de $0,61 \%$.

A sobreposição desse intervalo com várias classes do HAND pode ser devida à não identificação dos rios no IVDN, e/ou à barragem de Gramame-Mamuaba, representada em uma área maior no IVDN do que no HAND.

Novamente para a classe 1 do HAND a classe do IVDN que teve maior coincidência foi a 5, seguida pela classe 4 .

Em suma observa-se, a partir dos cruzamentos do IVDN, dos anos de 1989, 2001 e 2006 com o HAND que houveram divergências na classe 1 do IVDN, pois se esperava, que esta classe se coincidisse mais com a classe 1 do HAND, que representa as áreas mais baixas.

Essa incoerência pode ter sido causada pela baixa resolução espacial das imagens do satélite TM/Landsat-5, que fez com que os recursos hídricos, não caudalosos ou volumosos, não tenham sido bem representados no IVDN, e por isso, estas áreas identificadas no HAND, se espalharam sobre as outras classes nos mapas do IVDN. A classe 2 do IVDN teve grande parte de sua representatividade nas áreas com desnível de $2 \mathrm{~m}$ a $72 \mathrm{~m}$ de desnível, classes 2 e 3 do HAND, o que está dentro do esperado, tendo em vista esta classe representa também as áreas urbanizadas que historicamente vem crescendo próximo aos recursos hídricos, e ao litoral.

Já a classe 5 do IVDN foi a que teve maior coincidência com a classe 1 do HAND. Este fato pode ter ocorrido devido à calha dos rios serem estreitas, fazendo com que estes fossem representados pela mata ciliar.

Observou-se também, que a classe 5 coincidiu mais com a classe 2 do HAND. Esse fato, junto com a possibilidade de as regiões dos rios terem sido identificadas como vegetação densa, é forte indício de que, nos períodos estudados, a vegetação ciliar da bacia hidrográfica se encontrava bem preservada.

\section{CONCLUSÕES E RECOMENDAÇÕES}

Constatou-se que a proximidade com a rede de drenagem influenciou na resposta da vegetação ao IVDN, já que grande parte da vegetação densa se localiza na região próxima à rede de drenagem.

Em alguns locais observou-se até uma indistinção com os cursos d'água, o que pode ser um indício que as matas ciliares estão relativamente preservadas.

Verificou-se uma divergência entre os dados da cobertura e uso do solo com o IVDN. Ao cruzar os mapas do IVDN com os de cobertura e uso do solo, constatou-se que algumas áreas com alto IVDN coincidiram com a classe de cana-deaçúcar da cobertura e uso do solo.

Devido à grande extensão da área de estudo, os cultivos de cana-de-açúcar, podem estar em vários estágios fenológicos e a vegetação densa é composta de várias espécies, de portes diferentes, o que dificultou o encontro do limiar correto para distinguir essas diferentes espécies de vegetação.

Para valores baixos do IVDN houve uma coincidência com os dados de cobertura e uso do solo, pois, a classe de solo exposto/área urbana, de forma geral, apresentou uma boa coincidência com a faixa de IVDN próxima de zero.

Houve um aumento na degradação da bacia hidrográfica em relação ao uso do solo, no período de 1989 para 2006.

Essa degradação pode ter ocorrido, principalmente, devido a convergência da vegetação natural em terras agrícolas sem a utilização de técnicas conservacionistas, expansões urbanas desordenadas e áreas provenientes da mineração.

A metodologia utilizada nesta pesquisa mostrou-se satisfatória mediante os resultados encontrados, nos quais se pôde observar alterações ambientais, ocorridas no período estudado, e suas prováveis causas.

Todavia, de acordo com os resultados obtidos, faz-se necessário um estudo mais detalhado da estrutura das espécies de vegetação e suas respostas ao IVDN.

A aplicação da metodologia em uma área de estudo menor, para que se possam avaliar, de forma controlada, as respostas ao IVDN das várias espécies de vegetação e em vários estágios fenológicos, possibilitando com isso, a adoção de limites mais precisos para cada classe dos parâmetros adotados.

A utilização de imagens obtidas com intervalos mais curtos, por um período de análises mais longo, com uma melhor resolução 
espacial e com menos interferências; um estudo comparando uma série histórica de precipitação, para que se possa avaliar a relação da chuva com as respostas do IVDN.

\section{REFERÊNCIAS}

BISPO, P. C. \& VALERIANO, M. M. Efeitos de métodos de classificação e de escalas de mapeamento na percepção das relações entre geomorfometria local e classes de vegetação. In: SIMPÓSIO BRASILEIRO DE SENSORIAMENTO REMOTO, XIV, Natal. 2009. Anais... Natal: INPE, p. 2587-2594 (CDROM).

CHAVEZ, P. S. Image-based atmospheric corrections Revisited and improved. Photogrammetric Engineering \& Remote Sensing, v. 62, n. 9, p. 1025-1036, 1996.

COELHO, V. H. R. Monitoramento e análise da variação do nível d'água para estimativa da recarga do aquífero livre da bacia do rio Gramame - PB. João Pessoa, 2011. Dissertação (Mestrado), Federal da Paraíba.

DEB, D. \& TALUKDAR, B. Application of remote sensing and GIS tools in delineating environmentally-delicate-areas for optimum land use planning: a case study. World Environmental and Water Resources Congress Bearing Knowledge for Sustainability, ASCE, p. 3862-3875, 2011.

ERENO, D. Para evitar novos flagelos. Pesquisa FAPESP, São Paulo, v. 171, p. 16 - 21, 2010.

FERREIRA, R. A.; NETTO, A. O. A.; SANTOS, T. I. S.; SANTOS, B. L.; MATOS, E. L. Nascentes da sub-bacia hidrográfica do rio Poxim, estado de Sergipe: da degradação à restauração. Viçosa, Revista Árvore, v.35, n.2, p.265-277, 2011.

FITZ, P. R. Geoprocessamento sem complicação. São Paulo: Oficina de Textos, 160p., 2008.

GONG, W. \& LIU, T. Study on the vegetation coverage dynamic change of songhuajiang watershed based on RS and GIS. IEEE, p. 3612-3614, 2011.

MATHER, P. M. Computer processing of remotely-sensed images. School of Geography, The University of Nottingham, UK. Second Edition, 1999.

MELLO, B. A. J. \& LIMA, V. R. E. Diagnóstico geoambiental em microbacia hidrográfica do Semiárido brasileiro, a partir do uso de geotecnologias. Revista de Geografia (UFPE) v. 28, n. 1, p. 135, 2011.

PARAIIBA. Secretaria Extraordinária do Meio Ambiente, dos Recursos Hídricos e Minerais. (2000). Plano Diretor de Recursos Hídricos da Bacia do Rio Gramame. Relatório Final. v. 1. João Pessoa, PB, 247 p.

PEREIRA, M. M. E.; DOMECQ, F. A. M.; JIMENEZ, K. Q.; COLLISCHONN, W. Comparação entre o descritor de terreno HAND e o índice NDVI. In: SIMPÓSIO BRASILEIRO DE RECURSOS HÍDRICOS, XIX, 2011, Maceió. Anais...Maceio.

PONZONI, F. J. \& SHIMABUKURO, Y. E. Sensoriamento no estudo da vegetação. $1^{\text {a }}$ Edição. São José dos Campos: Editora Parênteses, 2007.

RAMOS, R. R. D.; LOPES, H. L.; JÚNIOR, J. C. F. M.; CANDEIAS, A. L. B.; FILHO, J. A. S. Aplicação do Índice da Vegetação por Diferença Normalizada (NDVI) na avaliação de áreas degradadas e potenciais para unidades de conservação. In: Simpósio Brasileiro de Ciências Geodésicas e Tecnologias da Geoinformação, III. 2010. Recife. Anais...Recife p. 1-6.

RENNÓ, C. D; NOBRE, A. D; CUARTAS, L. A.; SOARES, J. V. HODNETT, M. G; TOMASELLA, J; WATERLOO. HAND, a new terrain descriptor using SRTM-DEM: Mapping terra-firme rainforest environments in Amazonia. Remote Sensing of Environment., p. 3469-3481, 2008.

RIZZI, R. Geotecnologias em um sistema de estimativa da produção de soja: estudo de caso no Rio Grande do Sul. São José dos Campos. 2004 Tese (Doutorado em Sensoriamento Remoto), SP: INPE, p. 212.

ROUSE JÚNIOR, J. W.; HAAS, R. H.; SCHELL, J. A.; DEERING, D. W. (1973) Monitoring the vernal advancement and retrogradation (green wave effect) of natural vegetation. Texas A\&M University Remote Sensing Center College Station, Texas. Goddard Space Flight Center Greenbelt, Maryland, p. 120.

SÁ, I. I. S.; GALVÍNCIO, J. D.; MOURA, M. S. B.; SÁ, I. B. Uso do Índice de Vegetação da Diferença Normalizada (IVDN) para caracterização da cobertura vegetal da região do Araripe pernambucano. Recife, Revista Brasileira de Geografia Física, v. 1, n. 1, p. 28-38, 2008.

SILVA, M. R.; RIBEIRO, M. G.; CENTENO, J. A. S. Monitoramento de estiagens com imagens MODIS. In: SIMPÓSIO BRASILEIRO DE SENSORIAMENTO REMOTO, 13, Florianópolis. 2007. Anais... Florianópolis.

SILVEIRA, A; NOBRE, A. D; RODRIGUES, G. Computational Aspects in Mapping risk areas for São Paulo Metropolitan Zone applying the new HAND Terrain Model. São José dos Campos, 2010. In: CONFERENCE OF COMPUTATIONAL INTERDISCIPLINARY SCIENCES. Anais... São José dos Campos: INPE. SONG, C.; WOODCOCK, C. E.; SETO, K. C.; LENNEY, M. P.; MACOMBER, S. A. Classification and change detection using Landsat TM data: when and how to correct atmospheric effects Remote Sens. Environ. Elsevier Science, v.75, p.230-244, 2001. SCHIMDT, P. \& MORRISON, T. H. Watershed management in an urban setting: process, scale and administration, Elsevier, v. 29, p. 45- 52, 2012.

TIMOTHY O. R. \& OLGA T. Spatiotemporal dynamics of landscape pattern and hydrologic process in watershed systems. Journal of Hydrology, v. 404, p. 1-12, 2011.

Submetido em 29 de março de 2016 Aceito em 9 de janeiro de 2017 